Objectives: To estimate the prevalence of rheumatic disease and related factors in a Colombian population over 18 years of age in six Colombian cities Methods: A Cross-sectional analytical study was designed in people older than 18 years. A probabilistic stratified sampling method using three stages. The first stage of sampling was the selection of cartographic sectors in each city. The second stage of sampling was the blocks of each sector. The third stage of sampling was the homes of each block. All household members were surveyed. The sample size was calculated to be 6,528 people (2336 from Bogotá, 1220 from Medellín and Cali each, 746 from Barranquilla, 503 from Bucaramanga and Cúcuta each). The COPCORD questionnaire adapted for Colombia, was applied in the first stage by standardized interviewers. Positive cases were reviewed at home by a first year rheumatology fellow. To assess whether it is a rheumatic disease; the positive cases for a probable rheumatic disease were reviewed by a second year rheumatology fellow and reviewed again with laboratory and image studies by a certified rheumatologist to establish the definitive diagnosis

Results: 3,146 men and 3,547 women were included. Pain in the last 7 days not associated with trauma was reported in 3,213 (48\%) participants. The most frequent sites were knees (right $31 \%$, left $29 \%$ ), hands (right $25 \%$, left $24 \%$ ), lumbar spine (18\%) and shoulders (right 16\%, left 14\%). Table 1 depicts the prevalence of rheumatic diseases in Colombia

Table 1. Prevalence of Rheumatic Disease in Colombia

\begin{tabular}{lccc}
\hline & Prevalence (\%) & Variation Coefficient & $\mathrm{Cl} 95 \%$ \\
\hline Osteoarthritis & 10,81 & 6 & $9,68-12,06$ \\
Gout & 0,56 & 26 & $0,33-0,92$ \\
Fibromyalgia & 0,72 & 22 & $0,47-1,11$ \\
Soft Tissue Rheumatism & 25,82 & 6 & $11,60-19,93$ \\
Mechanic Low Back Pain & 7,24 & 7 & $6,28-8,34$ \\
Inflammatory Low Back Pain & 0,65 & 28 & $0,38-1,12$ \\
Spondyloarthritis & 0,39 & 51 & $0,08-0,48$ \\
Rheumatoid Arthritis & 1,49 & 15 & $1,12-1,98$ \\
Systemic Lupus Erythematosus & 0,05 & 56 & $0,02-0,16$ \\
Sjögren Syndrome & 0,08 & 61 & $0,02-0,27$ \\
Dermatomyositis & 0,03 & 100 & $0,00-0,23$ \\
Scleroderma & 0,02 & 100 & $0,00-14$ \\
CHIKV infection & 6,68 & 8 & $5,73-7,78$ \\
\hline
\end{tabular}

$\mathrm{Cl}$ : confidence interval; CHIKV: chikungunya virus.

Conclusions: Our study shows a similar prevalence to those worldwide in scleroderma, dermatomyositis, systemic lupus erythematosus, and spondyloarthritis. A lower prevalence was observed in Sjögren Syndrome, fibromyalgia, gout and osteoarthritis. A slightly higher prevalence of rheumatoid arthritis was observed in our population. The high prevalence of rheumatoid arthritis and soft tissue rheumatism should increase awareness in our governmental health entities given their long term disability risk

Disclosure of Interest: None declared

DOI: 10.1136/annrheumdis-2017-eular.5646

\section{FRI0695 SERIOUS INFECTION ACROSS BIOLOGIC TREATED PATIENTS WITH RHEUMATOID ARTHRITIS: RESULTS FROM A NATIONAL REGISTRY}

A.I. Rutherford $^{1}$, S. Subesinghe ${ }^{1}$, R. Byng-Maddick ${ }^{2}$, K. Hyrich ${ }^{3}$,

J.B. Galloway ${ }^{1} .{ }^{1}$ Academic Rheumatology Department, King's College London;

${ }^{2}$ Rheumatology, Homerton Hospital, London; ${ }^{3}$ Arthritis Research UK Centre for

Epidemiology, University of Manchester, Manchester, United Kingdom

Background: Infection is a complication of biologic therapy in RA.

Objectives: To describe the incidence and pattern of serious infection within the British Society for Rheumatology Biologics Register (BSRBR-RA) by drug.

Methods: The BSRBR-RA is a prospective observational study designed to evaluate the safety of biologics. Adverse events are coded using MedDRA defintitions. This analysis included patients with RA starting a biologic. They were considered at risk from their start date until 3 half-lives after stopping their biologic, death, first serious infection, or completion of three years of therapy, whichever came first. Event rates were compared across biologics using Cox proportional hazards with adjustment for age, gender, disease severity and duration, smoking, seropositivity, polypharmacy and baseline steroid usage.
Results: 19,282 patients were included in the analysis with combined follow-up time of 46,771 years. At baseline the mean age was 57 years, $76 \%$ female, mean disease duration 12.3 years and mean DAS28 6.1. 22\% were current smokers and $64 \%$ had a positive rheumatoid factor. The incidence of serious infection for each biologic and hazard ratios for serious infections including by subclass are tabulated.

A sensitivity analysis limiting to 1st biologic exposure only did not significantly alter the estimates. A second sensitivity analysis limiting to new starters from 2010 found certolizumab still had a lower point estimate but findings were no longer significant (HR 0.79, $\mathrm{Cl}$ 0.54-1.16).

Conclusions: Although the incidence of serious infection was lowest with certolizumab it is difficult to draw strong conclusions about comparative safety from observational studies due to channelling bias and unmeasured confounding. Rituximab and tocilizumab both had higher unadjusted rates of infection but in the adjusted model the rate was no different suggesting that patient factors as opposed to the drug itself were responsible for the observed difference.

Disclosure of Interest: A. Rutherford: None declared, S. Subesinghe: None declared, R. Byng-Maddick: None declared, K. Hyrich Grant/research support from: Pfizer, Speakers bureau: Abbvie, J. Galloway Consultant for: Roche, BMS, UCB, Pfizer

DOI: 10.1136/annrheumdis-2017-eular.1711

\section{FRI0696 IMPACT OF ADALIMUMAB THERAPY ON BRACHIAL ENDOTHELIAL FUNCTION AND LARGE ARTERY STIFFNESS IN PATIENTS WITH RHEUMATOID ARTHRITIS}

A.L. Demoux ${ }^{1}$, K. Aissi ${ }^{1}$, B. Chaudier ${ }^{2}$, S. Carijn ${ }^{3}$, P.-Y. Chouc ${ }^{3}$, H. De Baillou ${ }^{3}$, P. Rossi ${ }^{1} .{ }^{1}$ Internal medicine department, public hospital of Marseille; ${ }^{2}$ Internal Medicine Deprtement, Laveran Hospital; ${ }^{3}$ CONCERTO Association, Marseille, France

Background: Anti-TNF alpha treatment may improve endothelial function and mechanical properties of large artery stiffness in patients with inflammatory rheumatic diseases, however studies remain controversial.

Objectives: To study the effect of TNF alpha blockage with adalimumab for 24 weeks on brachial endothelial function and sub-clinical markers of atherosclerosis in patients with inflammatory rheumatic diseases.

Methods: A total of 26 patients ( 14 males, 12 females; mean age, $47 \pm 11$ years) with inflammatory rheumatic diseases (16, rheumatoid arthritis; 9, ankylosing spondylitis, 1, psoriasic rheumatism), resistant to disease-modifying antirheumatic drugs, were studied before the first infusion of adalimumab and again after 24 weeks of treatment. Endothelial function was assessed by measuring flow mediated dilatation using an ultrasound Doppler technique on the brachial artery. Other markers of sub clinical atherosclerosis were assessed by arterial stiffness via aortic pulse wave velocity, augmentation index and central blood pressure, and carotid intima-media thickness. Data for body mass index, disease activity using DAS-PCR and BASDAI, C-reactive protein, fasting glycaemia, and lipid profile were collected before treatment and after 24 weeks.

Results: 24 weeks of adalimumab therapy resulted in a reduction of disease activity score and serum levels of C-reactive protein. No significant differences were found in body mass index, total cholesterol, triglycerides and fasting glycaemia. Brachial blood pressure and heart rate remained similar, as well as carotid intima-media thickness. After 24 weeks of treatment with adalimumab, flow mediated dilatation improved significantly; central systolic and diastolic blood pressure decreased significantly; however central pulse pressure, augmentation index and aortic pulse wave velocity remained unchanged.

Conclusions: In patients with inflammatory rheumatic diseases, treatment with adalimumab for 24 weeks resulted in a significant improvement of endothelial function and central arterial pressure.

Disclosure of Interest: A. L. Demoux Grant/research support from: Abbvie, K. aissi: None declared, B. chaudier: None declared, S. carijn: None declared, P.-Y. chouc: None declared, H. de baillou: None declared, P. rossi: None declared DOI: 10.1136/annrheumdis-2017-eular.6128

\begin{tabular}{|c|c|c|c|c|c|c|}
\hline & Etanercept & Infliximab & Adalimumab & Rituximab & Tocilizumab & Certolizumab \\
\hline \multicolumn{7}{|l|}{ Primary Analysis } \\
\hline Follow-up (yrs) & 15314 & 8829 & 13071 & 5910 & 1963 & 1685 \\
\hline Infections (single failure) & 852 & 472 & 709 & 372 & 137 & 64 \\
\hline Incidence per 100 patient years $(95 \% \mathrm{Cl})$ & $5.56(5.20,5.95)$ & $5.35(4.89,5.85)$ & $5.42(5.04,5.84)$ & $6.29(5.69,6.97)$ & $6.98(5.90,8.25)$ & $3.80(2.97,4.85)$ \\
\hline Serious Infection Hazard Ratio $(95 \% \mathrm{Cl})$ & Ref & $0.94(0.84,1.06)$ & $0.97(0.88,1.07)$ & $1.15(1.01,1.30)$ & $1.22(1.02,1.47)$ & $0.65(0.51,0.84)$ \\
\hline Adjusted HR $(95 \% \mathrm{Cl})$ & Ref & $0.87(0.77,1.00)$ & $0.98(0.88,1.08)$ & $0.91(0.80,1.04)$ & $1.17(0.93,1.47)$ & $0.69(0.52,0.92)$ \\
\hline \multicolumn{7}{|c|}{ Adjusted Hazard Ratio By Infection Class (95\% Cl) } \\
\hline Sepsis/Bacteraemia & Ref & $0.83(0.41,1.66)$ & $1.04(0.57,1.91)$ & $2.08(1.14,3.80)$ & $1.83(0.63,5.35)$ & $1.03(0.24,4.41)$ \\
\hline Respiratory Infection & Ref & $1.16(0.96,1.39)$ & $1.23(1.04,1.45)$ & $1.03(0.83,1.28)$ & $1.61(1.15,2.25)$ & $0.96(0.63,1.46)$ \\
\hline Skin Infection & Ref & $0.84(0.66,1.06)$ & $0.65(0.52,0.82)$ & $0.54(0.39,0.75)$ & $0.71(0.40,1.24)$ & $0.27(0.11,0.67)$ \\
\hline Gastrointestinal Infection & Ref & $0.95(0.66,1.38)$ & $0.77(0.54,1.11)$ & $0.93(0.61,1.42)$ & $1.45(0.72,2.90)$ & $0.51(0.16,1.63)$ \\
\hline Bone/Joint Infection & Ref & $0.56(0.38,0.83)$ & $0.80(0.58,1.09)$ & $0.67(0.43,1.02)$ & $0.46(0.17,1.27)$ & $0.73(0.32,1.68)$ \\
\hline Genitourinary Infection & Ref & $0.74(0.50,1.07)$ & $1.18(0.87,1.59)$ & $1.15(0.79,1.68)$ & $0.67(0.27,1.66)$ & $0.55(0.20,1.52)$ \\
\hline Other & Ref & $0.54(0.31,0.91)$ & $1.08(0.74,1.58)$ & $0.72(0.41,1.29)$ & $1.15(0.49,2.67)$ & $0.50(0.16,1.60)$ \\
\hline
\end{tabular}

